\title{
An Audit of patients with Diabetes attending Accident and Emergency with Severe Hypoglycaemia
}

\author{
$T$ Shonibare, $K$ Seejore and R Moisey \\ Diabetes Department, Calderdale and Huddersfield NHS Foundation Trust, United Kingdom
}

\section{Introduction}

- Hypoglycaemia remains the major barrier to tight glycaemic control in diabetes.

- latrogenic hypoglycaemia is shown to cause significant morbidity and mortality with an increased rate of hospital admissions ${ }^{1,2}$.

- OHAs are considered lower risk for hypoglycaemia; however national, rather than individualised, targets for glycaemic control has resulted in more patients being aggressively managed. Sulphonylureas (SU) remain one of the main options for managing T2DM but the glucose independent action is associated with an increased risk of hypoglycaemia ${ }^{1,3}$.

\section{Aims}

- To evaluate patients attending the A\&E department with severe hypoglycaemia over August 2008 - February 2012 at a large acute Trust serving a population of 450,000 .

- To assess the impact of iatrogenic hypoglycaemia from SU.

\section{Methods}

Data was collated using the local A\&E coding database EDIS, inpatient management system PASWEB and General practice database.

\section{Results}

- Between August 2008 and February 2012, 434 patients attended A+E with a diagnosis of severe hypoglycaemia (229, 53\%male). 212 (49\%) were admitted and 33 (7.6\%) died. The average (range) age was 63.5(17-99)years, 321(74\%) had T2DM, 113 (26\%) had T1DM, 1 had Gestational DM.
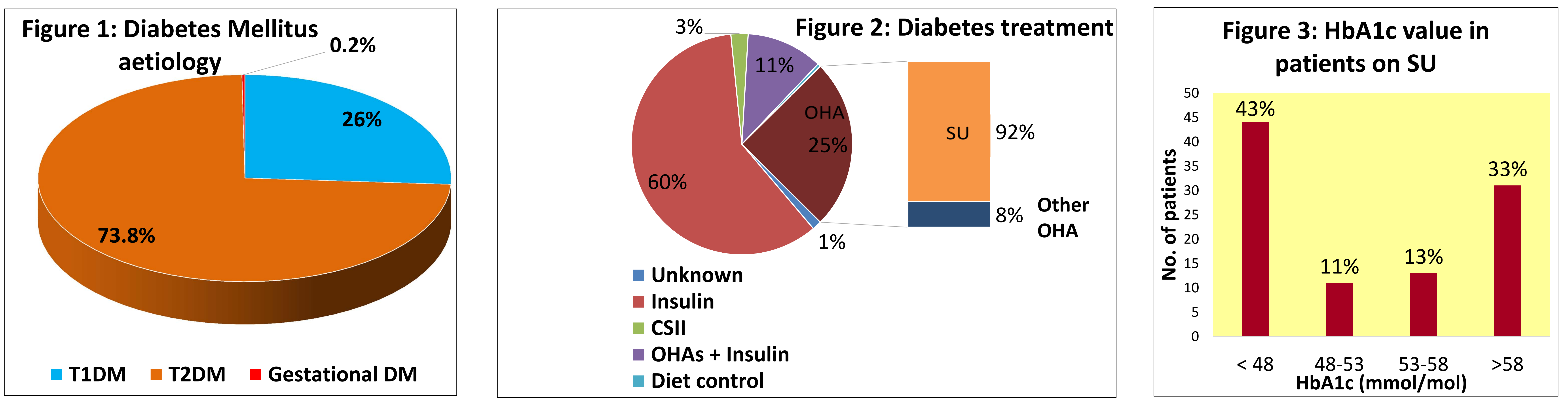

- 109 patients with T2DM (25\%) were managed with OHAs alone. Diabetes medication was known in 103 . Of these 92 (89.3)\% were on a SU (Gliclazide; 60.2\%, Glimepiride; 27.2\%, Glibenclamide; 1.9\%). 34 (33\%) were taking a SU alone, 51 (49.5\%) in combination with metformin. 71 (68.9\%)of patients on OHAs were admitted to hospital.
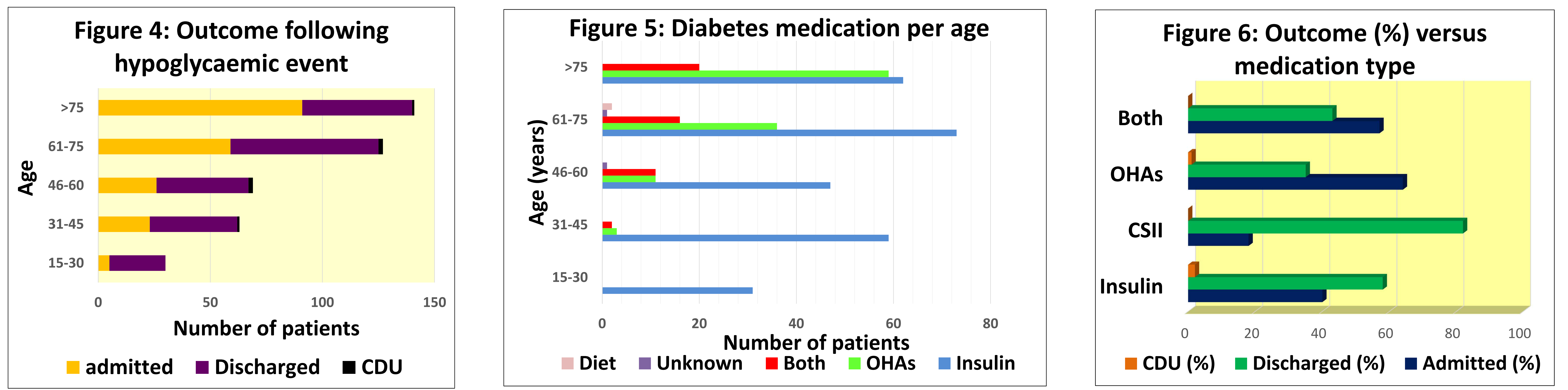

Compared to those on insulin, patients on OHAs were older (75.9yrs vs $60.0 \mathrm{yrs}, \mathrm{p}<0.0001$ ) with a lower $\mathrm{HbA} 1 \mathrm{C} \quad(51 \mathrm{mmol} / \mathrm{mol}$ vs 66 $\mathrm{mmol} / \mathrm{mol}, \mathrm{p}<0.0001)$ and were more likely to be admitted (67\% vs $44 \%) .44(43 \%)$ on a SU had an $\mathrm{HbA} 1 \mathrm{C} \leq 48 \mathrm{mmol} / \mathrm{mol}$ and the mean age was 77.6yrs.

\section{Discussion}

This audit highlights the increased risk of hypoglycaemia associated with SU therapy. Patients on OHAs were older with a lower HbA1C compared to those on insulin. In particular $43 \%$ of patients on SU therapy had an $\mathrm{HbA} 1 \mathrm{C} \leq 48 \mathrm{mmol} / \mathrm{mol}$. Using national targets puts this group of patients at an increased risk of severe hypoglycaemia; older patients should be given an individualised target for glycaemic control.

\section{References}

